\title{
Formulation and characterization of self-nano emulsifying drug delivery systems of lemongrass (cymbopogon citratus) essential oil
}

\author{
Tri Ujilestari a, Nanung Danar Dono a, Bambang Ariyadi a, Ronny Martien b, Zuprizal a, ${ }^{*}$ \\ a Department of Animal Nutrition and Feed Science, Faculty of Animal Science, Universitas Gadjah Mada, Yogyakarta, Indonesia \\ ${ }^{b}$ Department of Pharmaceutics, Faculty of Pharmacy, Universitas Gadjah Mada, Yogyakarta, Indonesia \\ * Corresponding author: zuprizal@ugm.ac.id
}

Article history

Received 27 February 2018

Revised 28 Mac 2018

Accepted 21 May 2018

Published Online 3 September 2018

\begin{abstract}
The present research was aimed to characterize the formula of self-nano emulsifying drug delivery systems (SNEDDS) for lemongrass essential oil. The observation variables included: particle size, zeta potential, and morphology. Meanwhile, the materials consisted of the mixtures of oils (lemongrass essential oil and carrier oil), surfactants, and cosurfactants. Carrier oils were screened as candidates for SNEDDS, and the formula was evaluated for transmittance and emulsification time. The value of the formulation component was lemongrass essential oils, carrier oil (Virgin Coconut Oil), surfactant (Tween 80), and co-surfactant (PEG 400) $=8.34,8.34,71.43$, and 16.67\% respectively. The formulation had a mean of the nanoemulsion droplet diameters of $20.7 \mathrm{~nm}$ with the polydispersity index $(\mathrm{PI}) 0.378$ and potential zeta $-73 \mathrm{mV}$. The transmission electron microscopy demonstrated spherical droplet morphology. This research produced SNEDDS of lemongrass essential oil with nanoparticle size that can be used as feed additive for poultry.
\end{abstract}

Keywords: Cymbopogon citratus; essential oil; nanoemulsion

\section{INTRODUCTION}

The increasing concern of antibiotic residues in poultry products has made many researchers try to find alternatives for the Antibiotic Growth Promoters (AGPs). One of the alternatives is the herbal feed additive such as essential oils (Eos) which known to have antibacterial, antiviral, antioxidant, antifungal, immunomodulator, hypolipidemic properties, and without residues (Gopi et al., 2014), anti-inflammatory, safe food product for human being (Kumar et al., 2014), stimulate feed intake, coccidiostats and antihelmintic activity (Suganya et al., 2016).

\section{LITERATURE REVIEW}

The lemongrass (Cymbopogon citratus) is a perennial, grows over the years, mainly in the tropical and savannah area. The main constituents of the lemongrass essential oil are citral (aldehydes geranial $(40-62 \%)+$ neral $(25-38 \%))$, the other main components are terpenes (myrcene - monoterpene and geranial - terpenic alcohol) (Negrelle \& Gomes, 2007; Ranitha et al., 2014). The citral shows antimicrobial activity against Gram-positive and Gram-negative bacteria as well as the fungi. However, myrcene has no individual antibacterial activity but do enhance activity when combined with others (Onawunmi, 1989; Onawunmi et al., 1984). In-vitro studies showed that essential oils of lemongrass have antimicrobial properties against Campylobacter jejuni, Clostridium perfringens (Wannissorn et al., 2005), Bacillus cereus, Escherichia coli, Klebsiella pneumonia, Staphylococcus aureus (Zulfa et al., 2016), and Salmonella typhi (Shin, 2005). A study by Mukhtar et al. (2012) showed that supplementing diets with lemongrass essential oils reduced the blood cholesterol without affecting overall growth performance of broiler chickens. This might be attributed to the ability of active substances to inhibit the hepatic 3-hydroxyl-3-3methylglutary co-enzyme A (HMGCOA).

Essential oils are mixtures of volatile components, which are composed of lipophilic substances in plants (Jeong et al., 2009). Nanoencapsulation of these oils in drug delivery systems have been proposed for improving the solubility, bioavailability, stability, and efficacy of essential oil-based formulation (Eid, et al., 2013; São Pedro et al., 2013). Low water solubility drug can be developed with self-nano emulsifying drug delivery systems (SNEDDS) (Savale, 2015; Wang, et al., 2009; Zhang et al., 2011). The SNEDDS is used for controlling the release rate of poorly water soluble drugs in both intestine and liver (Elnaggar, et al., 2009; Wang et al., 2009). The SNEDDS are the mixtures of oils, surfactants, and cosurfactants, sometimes including co-solvents, which emulsify under gentle agitation conditions, similar to those which would be encountered in the gastro-intestinal tract. It can lead to improved bioavailability of drug from gastro-intestinal tract (Pouton, 1997; Savale, 2015). Tween 80 is the nonionic surfactant that is emulsifying agents in the preparation of the stable oil in water pharmaceutical emulsions. PEG 400 can be used either to suspend agents or to adjust the viscosity and consistency of other suspending vehicles, which can act as emulsion stabilizers (Rowe et al., 2006). 


\section{METHODOLOGY}

\section{Materials}

The main material used in this study was lemongrass leaf, which obtained from a local suppliers in Bantul Regency, Yogyakarta, Indonesia. Chemicals and other materials used were: Tween 80 (Brataco, Yogyakarta, Indonesia), PEG 400 (Brataco, Yogyakarta, Indonesia), VCO (Healthy Co, Yogyakarta, Indonesia), soybean oil, canola oil, sunflower oil, and corn oil. Artificial gastric fluid (AGF) consisted of distilled water (Brataco, Yogyakarta, Indonesia), $\mathrm{NaCl}$ (Merck, Germany), and hydrochloric acid 37\% (Merck, Germany).

\section{The essential oil extraction}

The extraction technique of lemongrass essential oil was combined with steam distillation method. Leaves of $C$. citratus were chopped into small pieces (about 10-15 cm), the weight was about 4.5 kilogram, and it was loaded into the still distillation tank. Eight liters of water was added into the tank and the rid secured tightly. The plant materials were subjected there to steam distillation with the collection of the oils starting after a heating time of 30-50 minutes and continued until no more essential oil was obtained (4-8 hours).

\section{The formula of SNEDDS}

The solubility studies for carrier oil selection: five commonly oils used are; virgin coconut oil (VCO), canola oil, soybean oil, sunflower oil and corn oil, these five kinds of oils were screened.

SNEDDS preparation: SNEDDS was prepared using lemongrass essential oil, carrier oil VCO, non-ionic surfactant Tween 80, and cosurfactant PEG 400 stirred with a magnetic bar. The next, the formulations were subjected to sonication using ultrasonicator (J.P Selecta, Barcelona, Spain) for 10 minutes which reduces droplet size of the emulsion and water bath (Memmert $\mathrm{GmbH} \& \mathrm{Co} . \mathrm{KG}$, Schwabach, Germany) at $37^{\circ} \mathrm{C}$ for 15 minutes. After that, the formulation of SNEDDS was characterized (Sh, Abdelrazeik, \& Rakha, 2015).

Transmittance: $100 \mu \mathrm{l}$ of SNEDDS was accurately weighed and placed into $5 \mathrm{ml}$ aquadests. The mixture was homogenized with the aid of a vortex for 30 seconds. The homogenous mixing resulted and provided a clear visual display of the beginning of the SNEDDS creation. The obtained emulsion has been measured the absorbance at a wavelength of $650 \mathrm{~nm}$ (Pratiwi et al., 2016).

Determination of the emulsification time: In order to determine the emulsification time (the time needed to reach the emulsified and homogeneous mixture, upon dilution). $1 \mu 1$ of SNEDDS was added to $500 \mathrm{ml}$ of artificial gastric fluid at $37^{\circ} \mathrm{C}$ with gentle agitation using magnetic stirrer. The formula was assessed visually according to the rate of emulsification and the final appearance of the emulsion (Basalious et al., 2010) with the modification.

\section{The character of SNEDDS}

Particle size analysis: The emulsion droplet size and size distribution were determined using particle size analyzer (HORIBA SZ-100, Kyoto, Japan). Droplet size was analyzed using dynamic light scattering (DLS) technique. The samples were diluted with a ratio of 1:1000 (v/v) with distilled water and mixed for 1 min using a magnetic stirrer. The droplet size and polydispersity index (PDI) of the formulated nanoemulsion were measured (Sh et al., 2015).

Zeta potential analysis: The nanoemulsion stability is directed to the magnitude of the surface charge. The zeta potential of the selected formulations was determined using particle size analyzer (HORIBA SZ-100, Kyoto, Japan) (Balakumar et al., 2013).

Transmission electron microscopy (TEM): The morphology of SNEDDS was observed by TEM (JEOL JEM 1400, USA). After the sample dilution with water $(1: 1000)$, a sample drop was placed on a copper grid. The excess was drawn off with a filter paper. The samples were subsequently stained with $1 \%$ phosphotungstic acid solution for $30 \mathrm{~s}$ (Basalious et al., 2010).

\section{RESULTS AND FINDINGS}

\section{The preparation of SNEDDS}

Solubility studies for oil selection (Table 1) visual observation for solubility study of lemongrass essential oil in various oils show that VCO and canola oil have good solubility; on the other hand, soybean oil, sunflower oil, and corn oil have inadequate solubility. The further research combination of carrier oil, surfactant (Tween 80) and cosurfactant (PEG 400) (Table 2), VCO has the highest transmittance rate compared with canola and soybean oil which indicating the good dissolving ability. The VCO was selected for carrier oil, combined with Tween 80 and PEG 400 (Table 3) and obtained good transmittance value with low Tween 80 is the formula 1: $4: 1(\mathrm{ml})$, respectively. The result of VCO combination, lemongrass essential oil, Tween 80 and PEG 400 (Table 4) with ratio 0.5, 0.5, 4, $1 \mathrm{ml}$ respectively was the best formula with the highest lemongrass essential oil composition (8.33\%) for transmittance, visual observation, and emulsification time. Emulsification time means of self-emulsification assessment is visual estimation; the SNEDDS should disperse completely and quickly when subjected to aqueous dilution under agitation (Patel et al.,2011).

Table 1 Solubility study of lemongrass essential oil in various oils.

\begin{tabular}{cc} 
Oils & Visual observation \\
\hline VCO & Good \\
Soybean oil & Bad \\
Canola oil & Good \\
Sunflower oil & Bad \\
Corn oil & Bad \\
\hline
\end{tabular}

Table 2 Combination of carrier oil, Tween 80 and PEG 400.

\begin{tabular}{cccc}
\hline Carrier oil : Tween 80 : & \multicolumn{3}{c}{ \% Transmittance } \\
\cline { 2 - 4 } PEG 400 (ml) & VCO & Canola oil & Soybean oil \\
\hline $1: 1: 1$ & 86.5 & 23.2 & 26.3 \\
$1: 2: 1$ & 85.0 & 15.3 & 59.9 \\
$1: 3: 1$ & 96.1 & 67.0 & 49.7 \\
$1: 4: 1$ & 99.5 & 32.1 & 85.7 \\
$1: 5: 1$ & 99.8 & 72.4 & 85.9 \\
$1: 6: 1$ & 99.5 & 52.6 & 93.9 \\
$1: 7: 1$ & 99.4 & 99.5 & 99.1 \\
\hline
\end{tabular}

Table 3 The combinations without lemongrass essential oil.

VCO : Tween 80 : PEG $400(\mathrm{ml}) \quad \%$ Transmittance \pm SD

\begin{tabular}{lc}
$1: 1: 1$ & $9.37 \pm 5.27$ \\
$1: 2: 1$ & $55.00 \pm 2.05$ \\
$1: 3: 1$ & $70.40 \pm 13.36$ \\
$1: 4: 1$ & $98.43 \pm 0.85$ \\
$1: 5: 1$ & $98.73 \pm 0.92$ \\
$1: 6: 1$ & $99.13 \pm 0.67$ \\
$1: 7: 1$ & $98.60 \pm 0.36$ \\
\hline
\end{tabular}

Table 4 The combination of lemongrass essential oil.

\begin{tabular}{|c|c|c|c|}
\hline $\begin{array}{c}\text { Formulation } \\
\text { (VCO : } \\
\text { lemongrass } \\
\text { essential oil : } \\
\text { Tween } 80 \text { : PEG } \\
400)(\mathrm{ml})\end{array}$ & $\begin{array}{c}\% \\
\text { Transmittance } \\
\pm \text { SD }\end{array}$ & $\begin{array}{c}\text { Visual } \\
\text { observation }\end{array}$ & $\begin{array}{c}\text { Emulsification } \\
\text { time } \pm \text { SD }\end{array}$ \\
\hline $0.75: 0.25: 4: 1$ & $01: 04.0 \pm 0.01$ & Good & $99.5 \pm 0.12$ \\
\hline $0.5: 0.5: 4: 1$ & $01: 06.7 \pm 0.02$ & Good & $99.2 \pm 0.21$ \\
\hline $0.25: 0.75: 4: 1$ & $01: 10.4 \pm 0.02$ & $\mathrm{Bad}$ & $94.2 \pm 1.39$ \\
\hline
\end{tabular}




\section{The characteristics of SNEDDS}

Particle size analysis

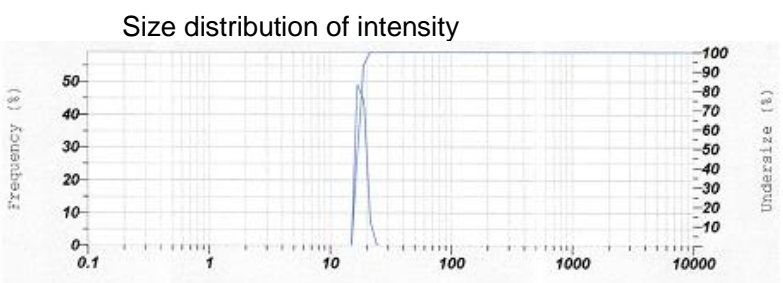

Size (d.nm)

Z-average (d.nm): 20.7 PDI: 0.378

Fig. 1 Particle size analysis of nanoemulsion.

In this current research, the particle size and polydispersity index (PI) (Fig 1.) values were obtained from testing the size and the particle size distribution of distilled water media which were $20.7 \mathrm{~nm}$ and 0.378 , respectively. The test was performed on distilled water media. Particle size distribution is used as uniformity (Pratiwi et al., 2016). Droplet size was the crucial factor in the SNEDDS performance (Jyothi \& Sreelakshmi, 2011), it determines the rate and the extent of drug release as well as drug absorption. The smaller particle size was the larger interfacial surface area which may lead to more rapid absorption and improve the bioavailability. The criteria of SNEDDS were the system with a mean droplet size below $200 \mathrm{~nm}$, and less than $50 \mathrm{~nm}$ indicating their efficiency as SNEDDS (Nasr et al., 2016). The particle size distribution was depending on the concentration of surfactant and co-surfactant (Taha et al., 2004). The polydispersity index (PI) less than 0.5 signaled a homogenous distribution, while a greater than 0.5 signaled a higher heterogeneous dispersion (Chavda et al., 2013).

\section{Zeta potential}

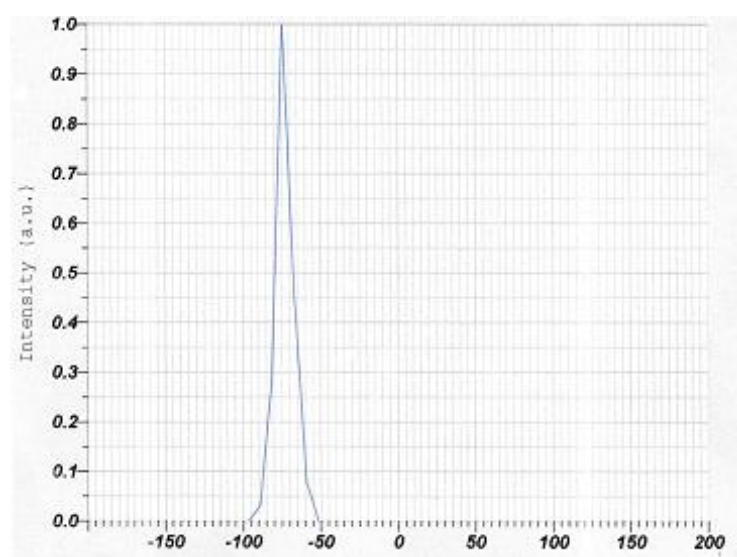

Zeta potential $(\mathrm{mV}):-73 \mathrm{mV}$

Fig. 2 Zeta potential analysis of nanoemulsion

The charge of the oil droplets was another property that was assessed for increased absorption of SNEDDS which was usually found to be negative due to the presence of free fatty acids (Kaur $e t$ al., 2013). Tween 80 is a non-ionic surfactant which decreases the zeta potential, because of the amphiphilic property of Tween 80 which deposited at the particle surface and caused the increasing size particle. Furthermore, it could protect surface charge the nanoemulsions led to decrease in zeta potential (Saeedi et al., 2015). The result (Fig 2.) showed that zeta potential was $-73 \mathrm{mV}$, would not exhibit threshold agglomeration as nanoemulsion was stabilized by a greater zeta potential (negative). Nanoparticles with zeta potential values greater than $+30 \mathrm{mV}$ or less than $-30 \mathrm{mV}$ have high degrees of stability; on the contrary, a low zeta potential value will eventually aggregate due to Van Der Waal inter-particle attractions (Bali et al.,
2011; Müller et al., 2001). The zeta potential of more than $\pm 60 \mathrm{mV}$ was excellent stability (Freitas \& Müller, 1998).

\section{Electron microscopic examination}

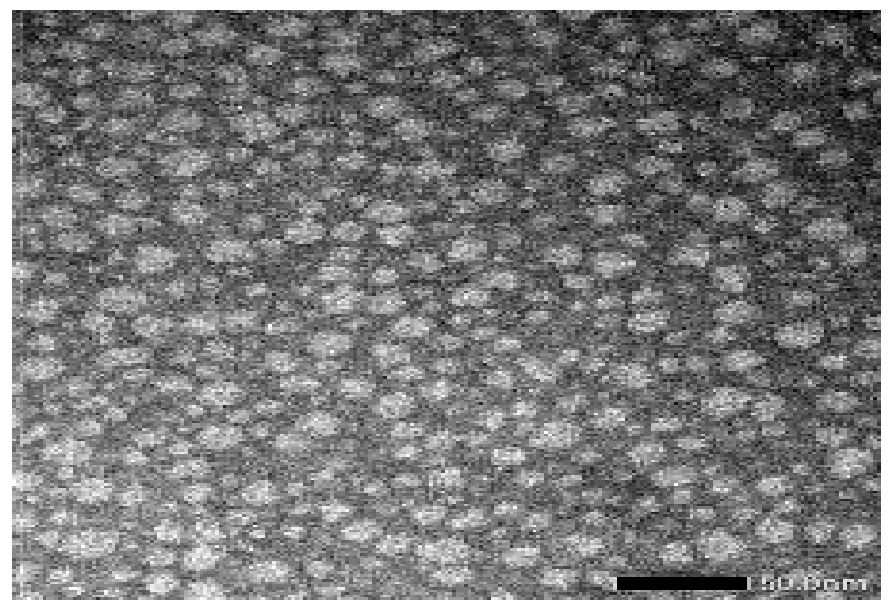

Fig. 3 Transmission electron micrograph of SNEDDS (mag $80 \mathrm{~K}$; 1000 fold with water)

The photograph of the transmission electron microscopy (TEM) was shown in Fig. 3. The nanoemulsion appeared as bright spots on the dark background. The emulsion droplets were spherical and the uniform with the size range between $16-25 \mathrm{~nm}$. The figures clearly illustrate that there are no signs of coalescence, indicating the formulation was physically stable (Bandyopadhyay et al., 2012).

\section{CONCLUSION}

The study showed that lemongrass essential oil could be employed as the oil phase for the development of SNEDDS. The SNEDDS with relatively good lemongrass essential oil content $(8.33 \%)$ was prepared with the mean emulsion droplet size of $20.7 \mathrm{~nm}$, the TEM images show nanoemulsion with no agglomeration. Furthermore, the SNEDDS appeared to be effective to improve the solubility.

\section{ACKNOWLEDGEMENT}

This research work is supported by DIKTI Ministry of Research, Technology, and Higher Education Indonesia with contract No: 4594/UN1-P.III/LT/DIT-LIT/2016.

\section{REFERENCES}

Balakumar, K., Raghavan, C. V., Abdu, S. 2013. Self nanoemulsifying drug delivery system (snedds) of rosuvastatin calcium: Design, formulation, bioavailability and pharmacokinetic evaluation. Colloids and Surfaces B: Biointerfaces, 112, 337-343.

Bali, V., Ali, M., Ali, J. 2011. Nanocarrier for the enhanced bioavailability of a cardiovascular agent: In vitro, pharmacodynamic, pharmacokinetic and stability assessment. International Journal of Pharmaceutics, 403(1), 4656.

Bandyopadhyay, S., Katare, O., Singh, B. 2012. Optimized self nanoemulsifying systems of ezetimibe with enhanced bioavailability potential using long chain and medium chain triglycerides. Colloids and Surfaces B: Biointerfaces, 100, 50-61.

Basalious, E. B., Shawky, N., Badr-Eldin, S. M. 2010. Snedds containing bioenhancers for improvement of dissolution and oral absorption of lacidipine. I: Development and optimization. International Journal of Pharmaceutics, 391(1), 203-211.

Chavda, H., Patel, J., Chavada, G., Dave, S., Patel, A., Patel, C. 2013. Selfnanoemulsifying powder of isotretinoin: Preparation and characterization. Journal of Powder Technology, 2013, 1-9.

Eid, A. M. M., Elmarzugi, N., El-Enshasy, H., Arafat, O. M. 2013. A novel swietenia macrophylla oil self-nanoemulsifying system: Development and evaluation. International Journal of Pharmacy and Pharmaceutical Sciences, 5(3) 639-644. 
Elnaggar, Y. S., El-Massik, M. A., Abdallah, O. Y. 2009. Selfnanoemulsifying drug delivery systems of tamoxifen citrate: Design and optimization. International Journal of Pharmaceutics, 380(1) 133-141.

Freitas, C., Müller, R. H. 1998. Effect of light and temperature on zeta potential and physical stability in solid lipid nanoparticle $\left(\sin { }^{\mathrm{TM}}\right)$ dispersions. International Journal of Pharmaceutics, 168(2), 221-229.

Gopi, M., Karthik, K., Manjunathachar, H. V., Tamilmahan, P., Kesavan, M., Dashprakash, M., et al. 2014. Essential oils as a feed additive in poultry nutrition. Advances in Animal Veterinary Sciences, 2(1), 1-7.

Jeong, M.-R., Park, P. B., Kim, D.-H., Jang, Y.-S., Jeong, H. S., Choi, S.-H. 2009. Essential oil prepared from cymbopogon citrates exerted an antimicrobial activity against plant pathogenic and medical microorganisms. Mycobiology, 37(1), 48-52.

Jyothi, B. J., Sreelakshmi, K. 2011. Design and evaluation of selfnanoemulsifying drug delivery system of flutamide. Journal of Young Pharmacists, 3(1), 4-8.

Kaur, G., Chandel, P., Harikumar, S. 2013. Formulation development of self nanoemulsifying drug delivery system (snedds) of celecoxib for improvement of oral bioavailability. Pharmacophore, 4(4), 120-133.

Kumar, M., Kumar, V., Roy, D., Kushwaha, R., Vaiswani, S. 2014 Application of herbal feed additives in animal nutrition-a review. International Journal of Livestock Research, 4, 1-8.

Mukhtar, A., Mohamed, K., Amal, O., Ahlam, A. 2012. Effect of different levels of lemon grass oil (lgo) as anatural growth promoter on the performance, carcass yields and serum chemistry of broiler chicks. Egyptian Poultry Science, 33, 1-7.

Müller, R., Jacobs, C., Kayser, O. 2001. Nanosuspensions as particulate drug formulations in therapy: Rationale for development and what we can expect for the future. Advanced Drug Delivery Reviews, 47(1), 3-19.

Nasr, A., Gardouh, A., Ghorab, M. 2016. Novel solid self-nanoemulsifying drug delivery system (s-snedds) for oral delivery of olmesartan medoxomil: Design, formulation, pharmacokinetic and bioavailability evaluation. Pharmaceutics, 8(20), 2-29.

Negrelle, R., Gomes, E. 2007. Cymbopogon citratus (dc.) stapf: Chemical composition and biological activities. Reviesta Brasileira de Plantas Medicinais, 9(1), 80-92

Onawunmi, G. O. 1989. Evaluation of the antimicrobial activity of citral. Letters in applied microbiology, 9(3), 105-108.

Onawunmi, G. O., Yisak, W.-A., Ogunlana, E. 1984. Antibacterial constituents in the essential oil of cymbopogon citratus (dc.) stapf. Journal of Ethnopharmacology, 12(3), 279-286.

Patel, J., Kevin, G., Patel, A., Raval, M., Sheth, N. 2011. Design and development of a self-nanoemulsifying drug delivery system for telmisartan for oral drug delivery. International Journal of Pharmaceutical Investigation, 1(2), 112-118.

Pouton, C. W. 1997. Formulation of self-emulsifying drug delivery systems. Advanced Drug Delivery Reviews, 25(1), 47-58.

Pratiwi, L., Fudholi, A., Martien, R., Pramono, S. 2016. Design and optimization of self-nanoemulsifying drug delivery systems (snedds) of ethyl acetate fraction from mangosteen peel (garcinia mangostana, 1.)
International Journal of Pharmatech of Pharmech Research, 9(6), 380387.

Ranitha, M., Nour, A. H., Sulaiman, Z. A., Nour, A. H. 2014. A comparative study of lemongrass (cymbopogon citratus) essential oil extracted by microwave-assisted hydrodistillation (mahd) and conventional hydrodistillation (hd) method. International Journal of Chemical Engineering and Applications, 5(2), 104-108.

Rowe, R. C., Sheskey, P. J., Weller, P. J. 2006. Handbook of Pharmaceutical Excipients (Vol. 6). London: Pharmaceutical press London.

Saeedi, M., Rafati, M. R., Morteza-Semnani, K., Yazdani Rostam, A., Kelidari, H. R. 2015. Evaluation of effect of tween 80 on characteristics of tadalafil $0.1 \%$ suspension. Pharmaceutical and Biomedical Research, $1(2), 35-43$

São Pedro, A., Santo, I., Silva, C., Detoni, C., Albuquerque, E. 2013. The use of nanotechnology as an approach for essential oil-based formulations with antimicrobial activity. Microbial Pathogens and Strategies for Combating Them (Méndez-Vilas, A., ed.) Formatex Research Center Pulisher, 2, 1364-1374.

Savale, S. 2015. A review - self nanoemulsifying drug delivery system (snedds). International Journal of Research in Pharmaceutical and Nano Sciences, 4(6), 385-397.

Sh, A., Abdelrazeik, A., Rakha, O. 2015. Nanoemulsion of jojoba oil, preparation, characterization and insecticidal activity against sitophilus oryzae (coleoptera: Curculionidae) on wheat. International Journal of Agriculture Innovations and Research, 4(1), 72-75.

Shin, S.-W. 2005. Anti-salmonella activity of lemongrass oil alone and in combination with antibiotics. Natural Product Sciences, 11(3), 160-164.

Suganya, T., Senthilkumar, S., Deepa, K., Muralidharan, J., Gomathi, G., Gobiraju, S. 2016. Herbal feed additives in poultry. International Journal of Science, Environment and Technology, 5(3), 1137-1145.

Taha, E. I., Al-Saidan, S., Samy, A. M., Khan, M. A. 2004. Preparation and in vitro characterization of self-nanoemulsified drug delivery system (snedds) of all-trans-retinol acetate. International Journal of Pharmaceutics, 285(1), 109-119.

Wang, L., Dong, J., Chen, J., Eastoe, J., Li, X. 2009. Design and optimization of a new self-nanoemulsifying drug delivery system. Journal of Colloid and Interface Science, 330(2), 443-448.

Wannissorn, B., Jarikasem, S., Siriwangchai, T., Thubthimthed, S. 2005. Antibacterial properties of essential oils from thai medicinal plants. Fitoterapia, 76(2), 233-236.

Zhang, J., Peng, Q., Shi, S., Zhang, Q., Sun, X., Gong, T., et al. 2011. Preparation, characterization, and in vivo evaluation of a selfnanoemulsifying drug delivery system (snedds) loaded with morinphospholipid complex. International Journal of Nanomedicine, 6, 34053414.

Zulfa, Z., Chia, C., Rukayadi, Y. 2016. In vitro antimicrobial activity of cymbopogon citratus (lemongrass) extracts against selected foodborne pathogens. International Food Research Journal, 23(3), 1262-1267. 